\title{
A percepção dos técnicos de enfermagem sobre o processo de acreditação hospitalar
}

\section{The perception of nursing technicians about the hospital accreditation process}

\author{
${ }^{1}$ Sebastião Ezequiel Vieira ezequielvvieira@hotmail.com \\ ${ }^{1}$ Marcelo Alves Paraíso \\ 1 Ilda Cecília Moreira da Silva \\ ${ }^{1}$ Tatiane de Assis Bernardo Vieira
}

\section{RESUMO}

O presente trabalho procurou analisar a visão do técnico de enfermagem sobre o processo de Acreditação Hospitalar. A pesquisa teve caráter qualitativo e foi realizada em um hospital geral de grande porte no interior de Minas Gerais, estando este ingressado em conquistar a certificação em nível 01. Em conformidade com o Comitê de Ética e Pesquisa do UniFOA(CAAE- 14288213.9.0000.5237) 18 sujeitos fizeram parte da pesquisa, sendo observado que nove profissionais associaram a Acreditação a uma ação importante para a promoção de melhorias no atendimento. Quando perguntados sobre sua inserção no processo de Acreditação, 12 dentre os 18 profissionais mencionaram não se sentirem inseridos no processo de acreditação. Ao se perguntar sobre as dificuldades quanto ao repasse das informações pelos supervisores, 13 técnicos mencionaram ter dificuldades de comunicação. A presente pesquisa mostrou a necessidade de um trabalho educativo voltado para tais profissionais, principalmente para instituições que buscam a certificação em nível 01 (segurança e estrutura) onde a inserção dos técnicos torna-se essencial para a promoção da qualidade assistencial. Somente com a melhora do processo de comunicação é possível que tais profissionais deixem a visão tecnicista e passem a entender plenamente os objetivos propostos pela Acreditação Hospitalar.

Palavras-chave: Acreditação. Pessoal técnico de saúde. Educação em saúde.

\begin{abstract}
This study aimed to analyze the nursing technician insight into the Hospital Accreditation process. The research was qualitative and was held in a large general hospital in Minas Gerais, which itself is joined to achieve certification level 01. In accordance with the Ethics and Research Committee of UniFOA (CAAE14288213.9.0000.5237) 18 subjects took part in the survey, which found that nine professional associated Accreditation to an important action to promote improvements in care. When asked about his inclusion in the Accreditation process, 12 among the 18 professionals mentioned they do not feel included in the accreditation process. When asked about the difficulties regarding the transfer of information by supervisors, 13 technicians reported having difficulty communicating. This research has shown the need for educational work related to such professionals, mainly for institutions seeking certification in level 01 (safety and structure) where the integration of technical it is essential to promote quality of care. Only with the improvement of the communication process is possible that these professionals leave the technical vision and start to fully understand the objectives proposed by the Hospital Accreditation.
\end{abstract}

Keywords: Accreditation. Allied health staff. Health education.

1 Unifoa (Centro Universitário de Volta Redonda) 


\section{INTRODUÇÃO}

A presente pesquisa é parte do trabalho de dissertação desenvolvida entre 2012 e 2013 no Mestrado Profissional em Ensino de Ciências da Saúde e do Meio Ambiente do Centro Universitário de Volta Redonda/ UniFOA. A investigação se desenvolveu em um Hospital do município de Muriaé, Minas Gerais, mais especificamente na Unidade de Terapia Intensiva na intenção de se observar a visão dos profissionais sobre o processo de Acreditação Hospitalar a ser implantando pelo respectivo hospital.

No Brasil a Acreditação Hospitalar começou a se tornar realidade no início dos anos noventa, com a publicação: Acreditação de Hospitais para a América Latina e Caribe. Hoje mais de dez anos após a inciativa são mais de 300 instituições hospitalares com certificações validadas pela Organização Nacional de Acreditação (ONA, 2011; NOVAES, 1992).

Nos hospitais são comuns à presença de equipes multidisciplinares (enfermagem, médicos, fisioterapeutas, nutricionistas, farmacêuticos, e outros) dentre estes profissionais os técnicos de enfermagem tem sua importância particular para o processo de Acreditação, porque sempre esteve inserido diretamente no tratamento dos pacientes, tornando-se indispensável o conhecimento destes profissionais sobre segurança e qualidade para que se efetue o processo de Acreditação Hospitalar (RAMOS, 2010; ONA 2010).

Diante do exposto, a presente investigação tem como objetivo discutir a visão do técnico de enfermagem sobre o processo de acreditação hospitalar.

\section{REVISÃO DA LITERATURA}

Na atualidade o serviço hospitalar busca a sua referência de qualidade em atendimento aos usuários seguindo os parâmetros estabelecidos pela Organização Nacional de Acreditação (ONA): Segurança e estrutura (nível 1), organização (nível 2), práticas de gestão de qualidade (nível 3) (ONA, 2010).

O Processo de Acreditação visa o a melhoria da qualidade de forma continua, onde é proporcionada a possibilidade de um aprimoramento, que vai estabelecendo de maneira progressiva novos padrões, devido a resultados de estudos da mesma instituição ou em comparação com outras organizações semelhantes (ONA, 2010).

A finalidade do referido procedimento é a busca da inexistência de falhas, evidentemente sabemos da impossibilidade dessa prática, entretanto, a busca incessante de problemas é que permite a condição necessária para orientar ações que desenvolvam uma gestão de qualidade. Observa-se um avanço no processo cultural dos funcionários de instituições que são motivadas a participar das certificações ofertadas por meio de reformulações no processo em educação e compromisso em longo prazo, tendo em vista o desenvolvimento dos processos e padrões dos resultados apresentados pela instituição (AZEVEDO, 1993; CAMPOS 2008).

Os serviços hospitalares têm buscado de forma incessante alcançar melhorias na qualidade dos atendimentos ofertados. Para atingirem este objetivo, necessitam alcançar os requisitos estipulados pela Organização Nacional de Acreditação, este órgão é um norteador para instituições brasileiras que buscam melhorias continuas na assistência.

Neste trabalho abordamos a realidade de um hospital geral de grande porte do interior de Minas Gerais na cidade de Muriaé, esta instituição no momento da realização do trabalho busca a acreditação hospitalar de nível 01. Para alcançar este objetivo é especificado como requisito a necessidade de apresentar condições que possibilitem a oferta de um serviço com segurança e uma estrutura adequada para os usuários que buscam seus serviços (ONA, op. cit., 2010). 
Dentro dos hospitais a equipe de enfermagem compõe o maior quantitativo de profissionais que trabalham diretamente com os pacientes, sendo seus serviços de extrema importância para o tratamento e recuperação dos usuários. Estes profissionais quando devidamente habilitados proporcionam: segurança, conforto e um atendimento que garante a recuperação da enfermidade.

Especialmente no ambiente hospitalar os técnicos compõem grande parte do contingente, principalmente quando nos referimos aos serviços prestados de maneira pessoal e direta aos usuários. Estes serviços são considerados essenciais para se garantir a qualidade da assistência à saúde (FREITAS, 2007).

Entendendo que a melhoria na qualidade da assistência a saúde passa pelo processo da orientação profissional, considera-se que é de suma importância um acompanhamento no processo de Educação permanente para se alcançar a certificação de acreditação hospitalar (ONA, 2010; FREITAS, op. cit., 2007).

Portanto, tendo em vista a acreditação hospitalar, observa-se que é de suma importância ter um trabalho voltado para a classe dos profissionais técnicos de enfermagem. Podemos agregar a importância deles no processo de acreditação hospitalar a partir de dois movimentos: Primeiro, compõem o maior quantitativo de profissionais no ambiente hospitalar, pois trabalham diretamente com os pacientes. Segundo, sua atuação quando bem orientada pode contribuir de maneira eficaz e também de forma preventiva no que tange a segurança dos pacientes no ambiente hospitalar, neste caso específico, as unidades de terapia intensiva (ONA, Op. Cit. 2010; FREITAS, op. cit., 2007).

A educação permanente com os técnicos torna-se imprescindível porque no ambiente de saúde se exige uma objetividade e uma subjetividade que são inerentes a esta área, visto fato que, o objeto que a constitui são humanos em cujas intervenções técnicas sofrem ação das relações interpessoais. Todas as profissões que se destinam ao cuidar são de equivalências ético-dependentes, ou seja, no ambiente hospitalar é indispensável à educação para que a ética seja exercida em todas as relações profissionais com os pacientes (RIOS, 2009; BACKER, 2008).

Nas últimas décadas houve uma grande evolução tecnológica mundial, esta também é evidente no ambiente hospitalar. Porém, infelizmente não se observa a mesma evolução nos aspectos que evolvem o comportamento profissional, os quais se mantiveram estacionados no cenário Brasileiro (BACKER, op. cit. 2008).

\section{MATERIAL E MÉTODO}

A pesquisa teve como percurso metodológico três etapas complementares e processuais, conforme disposto: a primeira constituída por intermédio de uma revisão da literatura; a segunda foi configurada com a aplicação de um questionário com seis perguntas, semi-estruturadas aplicado aos técnicos de enfermagem da Casa de Caridade de Muriaé Hospital São Paulo (CCMHSP). As perguntas realizadas se compõem da seguinte forma: (1) Qual é a sua visão sobre Acreditação hospitalar; 2) Você se sente inserido e acredita que suas opiniões estão sendo ouvidas neste processo de implantação da Acreditação Hospitalar? Justifique; 3) Como se previne as infecções pulmonares em pacientes com ventilação mecânica e em respiração espontânea nas unidades de terapia intensiva?; 4) Como se previne as infecções por trato urinário em unidades de terapia intensiva? 5) Como se previne as infecções ocasionadas por cateter em corrente sanguínea? Quais as principais dificuldades encontradas com respeito as informações que são repassadas pelos gerentes das unidades? Justifique. A terceira etapa foi constituída pela avaliação dos resultados.

Nesta pesquisa nos detemos a avaliar as perguntas um, dois e seis, tendo em vista o fato de atender as expectativas propostas pelo presente trabalho, que se centraliza em: entender qual é a visão do profissional técnico de enfermagem sobre o processo de acreditação hospitalar, sua inserção e o seu ponto de vista sobre a forma como a comunicação é repassada pelos supervisores sobre o assunto. 
Com relação à revisão da literatura, é de suma importância no trabalho porque é a partir das pesquisas já realizadas, que a hipótese do trabalho deve ser fundamentada, o referencial teórico demonstra a base teórica já existente que vai embasar a reflexão e argumentação do pesquisador (RIBEIRO, ET AL, 2004).Quanto à aplicação de questionário é considerado um dos instrumentos mais utilizado para obtenção de dados, não existe uma quantidade normativa de questões, porém sempre deve ser levada em conta a exaustão que pode levar um questionário com muitas perguntas, as quais podem ser abertas ou fechadas ou combinando as duas modalidades. As vantagens do questionário se da pela obtenção de informações em curto prazo, facilidade na tabulação, também garante o anonimato e economia de tempo e recursos financeiros. Por outro lado, observa-se as suas limitações que são demonstradas na devolução dos formulários, no grau de confiabilidade das respostas obtidas que podem variar, na dificuldade de formular perguntas especificas para cada grupo para se obter o melhor entendimento do assunto (BARROS, 2007).

No questionário implantado junto aos técnicos de enfermagem abordamos aspectos relacionados ao processo de acreditação hospitalar, buscando visualizar qual é o seu ponto de vista sobre a acreditação. Ressaltando que durante a coleta dos dados implementados pelo questionário, a CCMHSP estava realizando mudanças estruturais e processuais para pleitear a certificação junto a ONA de instituição acredita em nível 1 (Segurança e Estrutura).

A metodologia usa como proposta a perspectiva do método qualitativa. Este método de pesquisa responde a questões bem particulares. No tocante a ciências sociais, ela tem a preocupação com uma realidade que não pode ser quantificada, ou seja, trabalha com um mundo de significados, motivos e aspirações, o que corresponde a um espaço mais profundo dos relacionamentos, dos fenômenos dos quais não podem ser reduzidos á operacionalização de variáveis (MINAYO, 2004).

Dentro deste contexto teremos condições de avaliar numericamente os dados bem como compreender os motivos ou aspirações que levaram a determinadas reações e decisões.

A análise dos dados será feita mediante a interpretação pautada em referenciais teóricos ligadas ao tema e apresentados no decorrer do estudo.

Participaram da pesquisa 18 profissionais técnicos de enfermagem que atuam em duas unidades de terapia intensiva da CCMHSP. Cabe apontar que todos fizeram o preenchimento do termo de consentimento livre e esclarecido em conformidade com a resolução 196/96, atendendo a normativa do Comitê de Ética e Pesquisa (CAAE- 14288213.9.0000.5237).

\section{RESULTADOS E DISCUSSSÃO}

De acordo com Campos (2008), em estudo sobre a Acreditação Hospitalar, existem consideráveis melhoras mediante a adesão do processo estabelecido pela ONA, sendo otimizados os setores de gestão da qualidade, eficiência e eficácia financeira, organização dos processos e desenvolvimento da satisfação dos colaboradores, resultando na melhoria da qualidade no atendimento hospitalar.

Visto que o processo de acreditação envolve mais do que aspectos gerenciais, pois existe conjuntamente uma mudança de valores individuais e sociais que caracterizam em muitas situações uma mudança interior, evidenciamos referenciados em Manzo (2011), a necessidade de se pensar na melhoria da qualidade dos serviços para além da ordem do capital. 
Na análise das respostas os Técnicos de enfermagem serão identificados pela letra "T", sendo citadas assim como descritas nos questionários, desta forma justificamos o fato de não serem feitas as correções ortográficas.

Assim, podemos visualizar tal perspectiva ao questionar os técnicos na pergunta um do questionário Qual a sua visão sobre Acreditação Hospitalar? Onde os hospitais poderão oferecer um serviço de qualidade e segurança T(5). O certificado qualifica os serviços prestados, padroniza e sistematiza todo o serviço da instituição minimizando erros T(6). Ajuda os hospitais a obter melhoria em relação à qualidade da assistência T(11).

Algo relevante a ser observado é que nove técnicos de enfermagem de um total de dezoito, associaram o processo de acreditação como uma ação importante para se proporcionar melhorias, principalmente no que se refere à melhoria da qualidade dos serviços e também das medidas de segurança.

Diante dos relatos dos técnicos, é relevante salientar que para Manzo e colaboradores a equipe de enfermagem, ao adentrar no processo de acreditação desenvolve valores essenciais como o ato de cuidar:

"Individualmente, na família ou na comunidade, desenvolvendo importantes ações por meio do cuidado, responsabilizando-se pelo conforto, acolhimento e bem-estar dos pacientes” (MANZO, ET AL, 2012, p. 4).

Outro aspecto que emerge nos relatos dos técnicos segundo - segurança e humanização - reafirma a pesquisa realizada pelo autor supracitado:

\begin{abstract}
"Os profissionais abordaram que o funcionário inserido num serviço acreditado sente-se mais bem preparado para atender as necessidades dos clientes à medida que oferecem recursos materiais, técnicos e humanos mais qualificados pela padronização de rotinas e maior organização" (MANZO, ET $A L$, 2012, p.5).
\end{abstract}

Um aspecto importante a ser ressaltado é o fato de que este trabalho está articulado ao processo de certificação Hospitalar em nível 1 pela ONA, e se torna ainda mais importante visto que a realidade dos profissionais que participaram da pesquisa objetiva a certificação junto a ONA em nível 01, que especificamente trata de segurança e estruturas adequadas para se ofertar o serviço de cuidados de saúde no ambiente hospitalar (ONA, 2010).

Os nove técnicos restantes não apresentaram respostas relacionadas ao processo de Acreditação Hospitalar, ficaram restritos à discussão sobre os processos internos do Hospital.

Diante das respostas apresentadas pelos técnicos, podemos perceber a necessidade de um trabalho voltado especificamente para o processo de educação permanente, focando as demandas, os objetivos e a importância da Acreditação Hospitalar, bem como abordar métodos próprios de sensibilização dos profissionais técnicos de enfermagem, pois não foi possível perceber se há na verdade um desconhecimento dos referidos profissionais do que vem a ser tal processo.

Segundo Manzo (2012), para que o processo de Acreditação Hospitalar ocorra de forma eficaz, pressupõe-se que deva existir uma interligação entre os profissionais e os setores envolvidos no processo de mudança.

Devido à complexidade dos serviços prestados no ambiente hospitalar, a equipe de enfermagem deve compreender o seu papel, que por sua vez é de fundamental importância na implantação e continuidade do programa. 
A enfermagem, de acordo com a autora, ocupa uma quantidade significativa de profissionais envolvidos no referido processo, tornando-se evidente a importância do comprometimento destes profissionais no processo de acreditação.

Por outro lado, ainda, deve-se levar em consideração a medição e complexidade dos serviços realizados por estes profissionais no ambiente hospitalar. O que se busca salientar é que a enfermagem trabalha na execução dos serviços prestados pelo hospital, no entanto existe a necessidade de setores de apoio, como administração (suporte de equipamento e recursos materiais), lavanderia, farmácia, higiene e limpeza, dentre outros. Isso torna imprescindível a ação criteriosa destes profissionais na mediação da relação interpessoal destes setores.

Diante do exposto, a segunda pergunta: Você se sente inserido e acredita que suas opiniões estão sendo ouvidas neste processo de implantação da Acreditação Hospitalar? Os entrevistados deveriam justificar sua resposta. Desta forma buscamos investigar o envolvimento dos técnicos de enfermagem na implementação do processo de Acreditação realizado no CCMHSP: Me sinto inserida, mas não sei se minhas opiniões serão ouvidas devido as dificuldades de comunicação na enfermagem T(1). De uma forma sim, mas as vezes não somos ouvidos da forma que queremos sendo que na maioria das vezes não temos retorno dos nossos pedidos por falta de estrutura T(4). Não... nós não sabemos normas, não temos reuniões abertas onde nós possamos discutir qualquer tipo de caso T(15). Não... nunca ninguém veio até mim me explicar sobre acreditação T(17)

É notável que 12 entre 18 profissionais disseram ter dificuldades quanto a sua inserção do processo de Acreditação Hospitalar, é importante ressaltar também a contradição que emerge nos relatos apresentados, pois apesar de se sentirem inseridas no processo de acreditação, percebem a dificuldade para intervir nos procedimentos estabelecidos pelo hospital.

Nesse sentido, cabe refletir sobre a complexidade que envolve a hierarquização hospitalar: como se estabelecem os processos de decisão procedimental no hospital? Qual a postura do coordenador da equipe frente às opiniões dos técnicos? Como se estabelecem os diálogos no interior das equipes de enfermagem e entre os setores envolvidos na acreditação?

Com relação à dificuldade mencionada pelas técnicas de enfermagem, parece que se aproxima do exposto pela Manzo e colaboradores (2012) quando relata que em sua pesquisa um dos aspectos negativos da acreditação é a forma como se desenvolve sua implantação: como um processo de cima para baixo. Para os autores, a administração em sua grande maioria decide pela implementação dos processos sem informar antecipadamente a proposta à equipe de profissionais.

O que se percebe com os relatos mencionados é uma relação com o processo educativo descrito por Ramos (2001), em que se relaciona o capitalismo com o surgimento do pensamento de se apropriar do ser humano como forma de objeto para um fim estabelecido.

Esta característica ficou plenamente estabelecida no século XIX com o gradativo domínio da burguesia sobre novas modalidades de conhecimentos, ficando evidenciada a diferença entre o trabalho manual e o intelectual.

Nos relatos descritos pelos técnicos de enfermagem, observa-se a falta de interação entre os gestores e a classe dos profissionais técnicos, descrevem-se de forma clara os mesmos valores mencionados por Ramos (2001), em que se observa uma hierarquização do trabalho manual e o intelectual. Ficando os serviços de cuidados para os técnicos e auxiliares e o serviço intelectual a cargo do enfermeiro. 
Dentro de um processo de acreditação hospitalar, segundo a ONA (2010), o que se pretende é uma melhora da qualidade de forma permanente. Os profissionais técnicos de enfermagem, bem como todas as atividades que exercem, devem sofrer processos de melhorias de forma contínua.

Em relação a esse aspecto, o da subalternização provocada pela hierarquização laboral, Manzo e colaboradores (2012), menciona que “em relação às percepções negativas sobre a acreditação, a falta de valorização é uma queixa dos referidos profissionais” (p. 6). Os autores menciona que os profissionais não se sentem valorizados, relatando que os seus erros são notados e criticados, ao passo que os acertos e o alcance das metas não apresentam repercussões.

Assim, pensar em um processo de intervenção, via acreditação, justifica-se pela necessidade da comunicação entre os atores sociais envolvidos, pela liberdade e exposição de ideias e pelo respeito da gerência ao diversos setores e hierarquias institucionais.

Este fato nos remete à necessidade de um processo gerencial por parte dos enfermeiros, os quais são responsáveis pelos técnicos de enfermagem em transmitir a eles segurança quanto a se expressarem e colocarem seus pontos de vista de maneira aberta e franca.

Para tanto, um processo de liderança deve ficar bem estabelecido pelos enfermeiros responsáveis por estas equipes. De acordo com Furukawa (2011), a liderança é a competência mais importante presente nos gerentes de enfermagem. Assim os liderados devem sentir segurança para se expressarem e realmente ter convicção de que suas falas serão ouvidas.

Por outro lado, seis profissionais demonstraram em suas falas segurança sobre sua inserção no processo de acreditação: Me sinto inserido, pois faço parte da equipe... quando sinto que posso fazer algo melhor, nós conversamos chegando a um acordo se vai ou não ser implantado T(2). Sim... um dos pontos importantes da acreditação é saber ouvir a opinião mostrando sempre o respeito mútuo T(8).

Segundo Quinto Neto (2004), é fundamental que os profissionais percebam e compreendam a necessidade do processo de acreditação, pois, de outra forma poderão ignorar os objetivos, bem como as propostas da instituição.

Um aspecto que emerge nas falas dos técnicos e se relaciona com a inserção destes profissionais no processo é o fato de se ouvir a opinião dos colaboradores ou da necessidade de interação dos profissionais. Manzo e colaboradores (2012) em sua pesquisa também reforçam tal perspectiva ao afirmar que “os profissionais relatam, ainda, que o processo de acreditação proporciona clima organizacional favorável e propício para fortalecer as relações” (p. 6). No entanto, os autores ainda mencionam que a falta de integração entre os profissionais pode provocar problemas no cotidiano do ambiente hospitalar:

Os entrevistados mencionam a falta de integração da equipe multiprofissional e relatam a inexistência de coesão entre os profissionais, ainda que devessem estar unidos em busca da excelência dos serviços. A situação revelada contraria os princípios preconizados pela ONA, quanto ao trabalho em equipe interdisciplinar e o cuidado integral (MANZO ET. AL, 2012, p. 06).

Devido a essa situação, justifica-se a melhoria contínua do processo de comunicação entre as equipes que estão engajadas na busca do processo de certificação junto à ONA (ONA, 2010), e da elaboração do produto pretendido por este trabalho.

A pergunta seis do questionário: quais as principais dificuldades encontradas com respeito às informações que são repassadas pelos gerentes das unidades? Devia ser justificada, ela nos remete à percepção dos técnicos de enfermagem em relação às informações que são repassadas pelos seus supervisores diretos, no interior das unidades de terapia intensiva. 
Segundo Broca (2012), o processo de comunicação na enfermagem deve ser encarado como uma peça chave, conforme é considerado pela política da transversalidade.

Assim, considera-se a comunicação como elemento de extrema importância no processo do "cuidado", tendo como pressuposto a sua complexidade. Ao questionar os enfermeiros sobre tal procedimento, observamos que 13 entre os 18 sujeitos da pesquisa afirmam ter dificuldades quanto ao processo de comunicação: Pois $a$ comunicação é corrida, fica perdida no ar. Pedem coisas que a falta de estrutura não permite, como a falta de funcionários e equipamento T(4). As informações chegam através dos corredores T (15). Temos poucas informações, sempre que sabemos é de terceiros... T (16). Quando muda as coisas não somos avisados... Até o momento não temos informações objetivas sobre o que é acreditação T (17).

Segundo Berlo (2003), o processo de comunicação deve ser compreendido como uma interação, caracterizada quando dois indivíduos fazem inferências sobre os próprios papéis e assumem o ponto de vista um do outro. Assim, realmente existe a possibilidade de se estabelecer a comunicação de forma efetiva.

Em todos os momentos em que os técnicos se referem à falta de clareza, ou informações que chegam através de corredores, visualizamos uma grande dificuldade no que tange à reciprocidade na comunicação, visto que os supervisores, em determinados momentos, não estão se preocupando em se certificar que as informações repassadas estão ou não sendo compreendidas pelos receptores, neste caso especificamente, os técnicos de enfermagem.

Mediante as respostas observamos uma característica da visão tecnicista, visto que estes profissionais técnicos estão inseridos em um processo de certificação hospitalar nível I, porém não estão a par das informações sobre esta reformulação de gestão.

Assim ocorre como caracterizado por Ramos (2001) sobre a existência da visão tecnicista, em que os questionamentos e a visualização de todo o processo não fazem parte da função do técnico, sendo a função do pensamento intelectual a cargo do enfermeiro ${ }^{(15)}$.

De acordo com Spagnuolo (2007), as formas de comunicação são variadas e dentre as principais podemos mencionar o modelo linear, onde as informações são repassadas no sentido único, sendo colocado na condição de sujeito que emite a mensagem, e na condição de objeto, que recebe a informação. Esta situação pode ser visualizada com as falas de 06 sujeitos da pesquisa: Falta de clareza, pois falta passar informação de forma clara e objetiva $\mathrm{T}$ (1). Pois são raras as reuniões, falta de diálogo $\mathrm{T}$ (7). Temos poucas informações, sempre que sabemos é de terceiros... quando muda as coisas não somos avisados T (16).

Mediante as respostas dos técnicos de enfermagem, observa-se a forma linear de comunicação adotada pelos gerentes das unidades. Segundo Teixeira (1997), em contraste ao modelo linear, debruçamo-nos a fazer uma reflexão há o modelo dialógico que propõe e coloca o emissor na mesma condição de sujeito. O modelo dialógico confere o poder de reciprocidade de informações, direcionando o conhecimento de forma a atender as necessidades do emissor e o receptor, neste caso, o supervisor (enfermeiro) e o receptor (técnicos de enfermagem).

Diante da dificuldade na forma de transmissão das informações, observa-se como se faz importante um processo de educação permanente dentro das instituições que pretendem uma melhoria continua junto a ONA. 


\section{CONCLUSÃO}

O Programa de Acreditação Hospitalar tem possibilitado grandes inovações no cenário nacional, principalmente promovendo uma mudança na prestação dos serviços que á tempos não passava por mudanças ideológicas diferentes da visão tecnicista.

A partir da implantação do processo de acreditação hospitalar no cenário nacional, tem-se difundido uma mudança no comportamento dos indivíduos que compõem as instituições hospitalares, especialmente rompendo com o cuidado mecanizado que historicamente estão arraigados na cultura dos hospitais, não deixando de mencionar que passa a existir um modelo de excelência como alvo a ser buscado de maneira incessante.

Este estudo buscou aprofundar a reflexão sobre o processo de acreditação hospitalar e as possíveis intervenções que podem ser feitas a partir do serviço ofertado pela classe profissional dos técnicos de enfermagem. Reforçando a necessidade da inclusão destes profissionais a partir de um processo educacional que valorize a sua atividade dentro de um processo de acreditação hospitalar em nível 01.

Ressalta-se que dentre os obstáculos ao realizar a pesquisa destacamos a escassez de material literário que permeia a subjetividade do papel do técnico de enfermagem dentro do cenário da Acreditação Hospitalar. No entanto mediante as pesquisas obtivemos respostas que permitiram uma melhor visão dos profissionais, e, também como se sentem dentro deste novo modelo de gestão. Além disto, foram obtidas informações importantes sobre a visão dos profissionais técnicos de enfermagem a Acreditação Hospitalar.

Por meio do estudo notou-se que os profissionais técnicos de enfermagem associam o processo de acreditação como ação importante para se alcançar melhorias, principalmente quando se refere as medidas de segurança. Emergindo dentre os participantes a falta de consenso sobre os benefícios do programa de acreditação hospitalar, havendo a exposição de pensamentos restritos a problemas internos da instituição distantes dos conceitos e propósitos fundamentados pela ONA e o processo de acreditação hospitalar.

Essa ideia transmite a necessidade de uma abordagem educacional voltada para desfragmentação dos conceitos relacionados ao processo de Acreditação hospitalar. Visto fato, destes profissionais não compreenderem de forma abrangente a filosofia do processo de Acreditação Hospitalar, possivelmente não conseguirem contribuir de maneira plena, visto não compreenderem bem o contexto em que estão inseridos e os objetivos a serem alcançados.

\section{REFERÊNCIAS}

AZEVEDO, A.C. Indicadores de Qualidade e Produtividade em Serviços de Saúde. Rev Ind Qual Produt Ipea 1993; 1(1):49-54.

BACKES, D. S. et al. O papel do enfermeiro no contexto hospitalar: a visão de profissionais de saúde. Revista Ciência Cuidado Saúde. 2008 jul/set; 7(3):319-326

BARROS, A.J.S. e LESHFELD, N.A.S. Fundamentos de Metodologia Cientifica. $3^{\circ}$ Edição, SP : Pearson Prentice Hall, 2007.

BERLO, D.K. O processo da comunicação: introdução à teoria e à prática. $10^{\mathrm{a}}$ ed. São Paulo: Martins Fontes; 2003. 
BROCA, P.V; FERREIRA, M.A; Equipe de enfermagem e comunicação: contribuições para o cuidado de enfermagem. Rev Bras Enferm, Brasília 2012 jan-fev; 65(1): 97-103

CAMPOS, L. I. Impacto da implantação em hospitais do sistema de gestão da qualidade, baseado nos requisitos de nível 1, 2, 3 do Sistema Brasileiro de Acreditação ONA. 2008 a. 133 f. Dissertação (Mestrado em Infectologia e Medicina Tropical) - Faculdade de Medicina, Universidade Federal de Minas Gerais (UFMG), Belo Horizonte.

FREITAS, G.F; OGUISSO, T. Perfil de profissionais de enfermagem e ocorrências éticas, Acta Paul Enferm, 2007 - SciELO Brasil.

FURUKAWA, P.O, CUNHA,I.C.K.O (Profile and competencies of nurse managers at accredited hospitals). Rev. Latino-Am. Enfermgem. 2011; 19(1):106-14.

NOVAES, H.M; PAGANINI, J.M. Garantia de qualidade: acreditação de hospitais para América Latina e o Caribe. Washington (DC): Federação Brasileira de Hospitais; 1992. (Série Silos, 13).

MANZO B.F; RIBEIRO, H.C.T.C; BRITO, M. J.M; ALVES, M. As percepções dos profissionais de saúde sobre o processo de acreditação hospitalar. Ver. Enfem. UERJ, Rio de Janeiro, 2011 out/dez; 19(4):571-6

MANZO, B.F; BRITO, M.J.M; CORRÊA, A.R. implicações do processo de acreditação hospitalar no cotidiano de profissionais de saúde. Rev. Esc. Enferm USP, SP, 2012; 46(2):388-94

MINAYO. Pesquisa Social. Petropólis, Edição 23, 2004.

ONA - Organização Nacional de Acreditação. Acessado em dezembro de 2011. Brasil - DF. Disponível em: (https://www.ona.org.br/OrganizacoesCertificadas)

ONA - Organização Nacional de Acreditação. Manual Brasileiro de Acreditação. Brasília (DF); 2010.

QUINTO NETO A. BITTAR O.J.N. Hospitais: administração da qualidade e acreditação de organizações complexas. Porto Alegre: dacasa; 2004. 315 p.

RAMOS, M.N. A pedagogia das competências: autonomia ou adaptação? São Paulo (SP), Editora Cortez, 2001.

RAMOS, M. Trabalho, educação e correntes pedagógicas no Brasil: um estudo a partir da formação dos trabalhadores técnicos da saúde. Rio de Janeiro: EPSSJV, UFRJ 2010.

RIBEIRO, U; CRUZ, C. Metodologia Cientifica: Teoria e Prática, 2º Edição, RJ, 2004.

RIOS, I. C. Humanização: a essência da ação técnica e ética nas práticas de saúde. Rev. bras. educação médica. vol.33 no.2 Rio de Janeiro Apr./June 2009.

SPAGNUOLO S.R; PEREIRA M.L.T - Práticas de saúde em Enfermagem e Comunicação: um estudo de revisão da literatura. Ciência \& Saúde Coletiva, 12(6):1603-1610, 2007.

TEIXEIRA RR. Modelos comunicacionais e práticas de saúde. Interface - Comunic, Saúde, Educ 1997;1(1):7-42. 